OPEN ACCESS

Check for updates

\section{Efficacy and safety of gastrointestinal bleeding prophylaxis in critically ill patients: systematic review and network meta-analysis}

\author{
Ying Wang, ${ }^{1}$ Zhikang Ye, ${ }^{1,2}$ Long Ge, ${ }^{3}$ Reed A C Siemieniuk, ${ }^{2,4}$ Xin Wang, ${ }^{1}$ Yingkai Wang, \\ Liangying Hou, ${ }^{3}$ Zhuo Ma, ${ }^{1}$ Thomas Agoritsas, ${ }^{2,5}$ Per Olav Vandvik, ${ }^{6}$ Anders Perner, ${ }^{7}$ \\ Morten H Møller, ${ }^{7}$ Gordon H Guyatt, ${ }^{2}$ Lihong Liu ${ }^{1}$
}

\section{ABSTRACT}

OBJECTIVE

To determine, in critically ill patients, the relative impact of proton pump inhibitors (PPIs), histamine-2 receptor antagonists (H2RAs), sucralfate, or no gastrointestinal bleeding prophylaxis (or stress ulcer prophylaxis) on outcomes important to patients.

\section{DESIGN}

Systematic review and network meta-analysis.

\section{DATA SOURCES}

Medline, PubMed, Embase, Cochrane Central Register of Controlled Trials, trial registers, and grey literature up to March 2019.

\section{ELIGIBILITY CRITERIA FOR SELECTING STUDIES AND METHODS}

We included randomised controlled trials that compared gastrointestinal bleeding prophylaxis with PPIs, H2RAs, or sucralfate versus one another or placebo or no prophylaxis in adult critically ill patients. Two reviewers independently screened studies for eligibility, extracted data, and assessed risk of bias. A parallel guideline committee (BM) Rapid Recommendation) provided critical oversight of the systematic review, including identifying outcomes important to patients. We performed random-effects pairwise and network meta-analyses and used GRADE to assess certainty of evidence for each outcome. When results differed between low risk and high risk of bias studies, we used the former as best estimates. RESULTS

Seventy two trials including 12660 patients proved eligible. For patients at highest risk ( $>8 \%)$ or high risk (4-8\%) of bleeding, both PPIs and H2RAs probably reduce clinically important gastrointestinal bleeding

\section{WHAT IS ALREADY KNOWN ON THIS TOPIC}

Most patients at high risk of gastrointestinal bleeding receive acid suppression during a stay in intensive care

The practice of gastrointestinal bleeding prophylaxis (often referred to as stress ulcer prophylaxis) has generated controversy

\section{WHAT THIS STUDY ADDS}

For higher risk critically ill patients, PPIs and H2RAs likely result in important reductions in gastrointestinal bleeding compared with no prophylaxis; for patients at low risk, the reduction in bleeding may be unimportant

Both PPIs and H2RAs may increase the risk of pneumonia

Evidence failed to support differences in a number of outcomes, including mortality compared with placebo or no prophylaxis (odds ratio for PPIs 0.61 ( $95 \%$ confidence interval 0.42 to 0.89 ), $3.3 \%$ fewer for highest risk and $2.3 \%$ fewer for high risk patients, moderate certainty; odds ratio for $\mathrm{H} 2 \mathrm{RAs}$ 0.46 ( 0.27 to 0.79$), 4.6 \%$ fewer for highest risk and $3.1 \%$ fewer for high risk patients, moderate certainty). Both may increase the risk of pneumonia compared with no prophylaxis (odds ratio for PPIs 1.39 (0.98 to 2.10), 5.0\% more, low certainty; odds ratio for H2RAs 1.26 (0.89 to 1.85 ), $3.4 \%$ more, low certainty). It is likely that neither affect mortality (PPIs 1.06 (0.90 to 1.28), $1.3 \%$ more, moderate certainty; H2RAs 0.96 (0.79 to 1.19 ), $0.9 \%$ fewer, moderate certainty). Otherwise, results provided no support for any affect on mortality, Clostridium difficile infection, length of intensive care stay, length of hospital stay, or duration of mechanical ventilation (varying certainty of evidence).

\section{CONCLUSIONS}

For higher risk critically ill patients, PPIs and H2RAs likely result in important reductions in gastrointestinal bleeding compared with no prophylaxis; for patients at low risk, the reduction in bleeding may be unimportant. Both PPIs and H2RAs may result in important increases in pneumonia. Variable quality evidence suggested no important effects of interventions on mortality or other in-hospital morbidity outcomes.

SYSTEMATIC REVIEW REGISTRATION

\section{Introduction}

Critically ill patients in intensive care units are at risk of gastrointestinal bleeding (for example, from stress ulceration). ${ }^{1}$ Authorities have suggested gastrointestinal bleeding prophylaxis is necessary to optimise the care of critically ill patients (often referred to as stress ulcer prophylaxis). Most patients at high risk receive acid suppression during intensive care. ${ }^{23}$ Proton pump inhibitors (PPIs) are the most common prophylactic agent, followed by histamine- 2 receptor antagonists (H2RAs); clinicians seldom use sucralfate and antacids. ${ }^{24}$

Many published systematic reviews and metaanalyses have summarised randomised controlled trial evidence addressing the efficacy and safety of interventions for gastrointestinal bleeding prophylaxis, ${ }^{5-10}$ including a network meta-analysis conducted by members of our team. ${ }^{5}$ Results provided support for prophylaxis, but raised concerning issues, particularly
PROSPERO CRD42019126656. 
nosocomial pneumonia. Much of the releveant evidence was, however, of low or very low quality.

Since the publication of the last network metaanalysis, several trials have been published, ${ }^{11-14}$ including a large, international, multicenter randomised controlled trial (the SUP-ICU trial). ${ }^{14}$ This trial compared pantoprazole with placebo and concluded that pantoprazole did not reduce mortality or a composite secondary outcome of "clinically important events" and questioned the routine use of PPIs in critically ill adults.

Because of new evidence suggesting a decrease in the frequency of bleeding, and new awareness of the possible limited morbidity associated with many bleeds, the practice of gastrointestinal bleedingprophylaxis has generated controversy. ${ }^{15}$ Moreover, observational studies have reported substantial increases in nosocomial pneumonia and Clostridium difficile infection with the use of acid-suppressive drugs, ${ }^{1617}$ raising concern that harms may outweigh benefits.

We conducted an updated systematic review and network meta-analysis on the potential benefits and harms of gastrointestinal bleeding prophylaxis with PPIs, H2RAs, and sucralfate in critically ill patients. This review is part of the $B M J$ Rapid Recommendations project, a collaborative effort from the MAGIC Evidence Ecosystem Foundation (www.magicproject.org) and The BMJ. The aim of the project is to respond to new, potentially practice-changing evidence and provide a trustworthy practice guideline in a timely manner underpinned by best evidence. ${ }^{18}$ In this case, the stimulus was the SUP-ICU trial. ${ }^{14}$ This systematic review informs a $B M J$ Rapid Recommendation (box 1).

\section{Methods \\ Protocol registration}

We registered the protocol for this systematic review with PROSPERO (CRD42019126656).

\section{Guideline panel and patient involvement}

In accordance with the BMJ Rapid Recommendations process, a guideline panel provided critical oversight during the review process, which included identifying populations, subgroups, and outcomes of interest. The guideline panel consisted of content experts, criti cal care clinicians, gastroenterologist, pharmacists,

\section{Box 1: Linked resources in this BMJ Rapid Recommendations cluster}

- Ye Z, Blaser AR, Lytvyn L, et al. Gastrointestinal bleeding prophylaxis for critically ill patients: a clinical practice guideline. BMJ 2019;367:16722

- Summary of the results from the Rapid Recommendation process

- Wang Y, Ye Z, Ge L, et al. Efficacy and safety of gastrointestinal bleeding prophylaxis in critically ill patients: systematic review and network meta-analysis. $B M$ J 2019;367:16744

- Review and network meta-analysis of all available randomised trials that assessed prevention of gastrointestinal bleeding in critically ill patients

- MAGICapp (https://app.magicapp.org/public/guideline/j96g2L)

- Expanded version of the results with multilayered recommendations, evidence summaries, and decision aids for use on all devices methodologists, former patients, and a patient care giver. Patients received personal training and support to optimise contributions throughout the guideline development process.

\section{Search strategy}

Our literature search, developed in collaboration with a research librarian, added the brand, generic and experimental names of PPIs, H2RAs, and sucralfate to the original search terms from our previous network meta-analysis (see appendix 1 on bmj.com). The search included Medline and Embase, the Web of Science, Cochrane Central Register of Controlled Trials (CENTRAL), International Clinical Trials Registry Platform (ICTRP), clinicaltrials.gov from January 2017 to March 2019 (our previous network meta-analysis searched from inception to April 2017), and a PubMed search for studies not yet indexed or not found in Medline and Latin American and Caribbean Health Sciences Literature (LILACS). Reviewers also searched the abstracts of the past two years of proceedings for the following conferences: Digestive Disease Week, United European Gastroenterology Week, European Society of Intensive Medicine, and Society of Critical Care Medicine. The reviewers scanned the reference lists of included studies and relevant systematic reviews to identify potential eligible studies.

\section{Study selection}

Two reviewers independently performed the study selection, including screening titles and abstracts, and evaluating full-text eligibility of potentially eligible studies. Reviewers resolved disagreements by discussion or by consultation with a third reviewer.

We included randomised controlled trials that compared the efficacy and safety of gastrointestinal bleeding prophylaxis, PPIs, H2RAs, or sucralfate versus one another or placebo or no prophylaxis in adult critically ill patients at risk of gastrointestinal bleeding regardless of location. We did not contact authors of studies, and we excluded studies that did not report sufficient information to pool data (for example, uncertain number of events or number of patients in each group). We applied no restriction based on dose or route of administration, duration of prophylaxis, or language of publication.

Outcomes included mortality at the longest followup reported, clinically important gastrointestinal bleeding, pneumonia, $C$ difficile infection, overt gastrointestinal bleeding, length of stay in intensive care, length of hospital stay, and duration of mechanical ventilation. We accepted study definitions of overt bleeding, typically defined as hematemesis, melaena, haematochezia, or coffee-grounds emesis or aspirate without additional characteristics of clinically important gastrointestinal bleeding. We accepted study definitions of clinically important gastrointestinal bleeding, which typically included evidence of upper gastrointestinal bleeding with any of the following: significant haemodynamic changes not explained by other causes, need for transfusion of more than two 
units of blood, significant decrease in haemoglobin level, evidence of bleeding on upper gastrointestinal endoscopy, or need for surgery to control bleeding. When extracting data on overt bleeding, we included clinically important gastrointestinal bleeding. We accepted the definitions of pneumonia and $C$ difficile infection used in each trial.

\section{Data extraction}

For each eligible study, two reviewers independently abstracted the following items with adjudication by a third reviewer: study characteristics (year of publication and country); population characteristics (sample size, age, proportion of males, type of intensive care unit, risk factors for gastrointestinal bleeding, and proportion of mechanical ventilation and enteral nutrition); description of interventions and comparators (the name, dose, administration route, frequency, and duration); and outcomes and their definitions.

\section{Risk of bias assessment}

Two reviewers independently assessed risk of bias with adjudication by a third reviewer, using a modified Cochrane Collaboration tool (Guyatt and Busse, modification of Cochrane tool to assess risk of bias in randomised trials) that includes sequence generation, allocation sequence concealment, blinding, missing outcome data (we judged high risk of bias if the rate of missing data was more than 5\%), and other bias (in this case, early trial discontinuation due to benefit). Each criterion was judged as definitely or probably satisfied (low risk of bias), or probably or definitely not satisfied (high risk of bias). We did not summarise the overall risk of bias for studies across criteria.

\section{Data synthesis and analysis}

For each direct comparison for each outcome, we performed a Bayesian random-effects pairwise metaanalysis assessing heterogeneity with visual inspection of forest plots and the $\mathrm{I}^{2}$ statistic. ${ }^{19}$ We calculated odds ratios and corresponding 95\% credible intervals (the Bayesian equivalent of frequentist confidence intervals) for all dichotomous outcomes, and mean differences with corresponding 95\% credible intervals for continuous outcomes. We performed Egger test to assess the publication bias when 10 or more studies were available for a comparison. ${ }^{20}$

We performed a Bayesian random-effects network meta-analysis using Markov-chain Monte-Carlo simulation. $^{2122}$ We used three chains with 100000 iterations after an initial burn-in of 10000 and a thinning of 10 . We assessed the convergence based on trace plots and the Brooks-Gelman-Rubin statistic, with an acceptable threshold of $<1.05$ for all nodes. We used non-informative priors for all parameters and assumed a common heterogeneity parameter for all treatment comparisons. We calculated the odds ratios and corresponding 95\% credible intervals of network estimates with a consistency model. For all dichotomous outcomes, we calculated the absolute treatment effects of the network estimates based on the odds ratios and the event rates in the placebo arm in SUP-ICU trial using the modified Dias model, incorporating lines into the model. ${ }^{23}$ The guideline panel searched for evidence on risk factors for bleeding and proposed four categories of risk of bleeding (linked BMJ Rapid Recommendation shows details on calculating baseline risks) and calculated absolute effects for each category for both clinically important gastrointestinal bleeding and overt bleeding. For continuous variables, when absent in reports, we estimated standard deviations from standard errors, $P$ values, ranges, or interquartile ranges or, if none of these options was available, from other studies included in our network meta-analysis using a linear regression approach. ${ }^{24}$

For each paired comparison, we used conventional pairwise random-effects meta-analysis to inform the direct estimates and, through a node-splitting method, obtained the indirect estimates. We evaluated the ranking probabilities and calculated surface under the cumulative ranking curves (SUCRA). We used the node-splitting method to assess local incoherence (incoherence was assessed using both this test and the difference in point estimates and overlap of the credible intervals). ${ }^{25}$ We assessed the incoherence of the entire network using global $\mathrm{I}^{2}$ statistics. A comparisonadjusted funnel plot of treatment estimates addressed small-study effects. ${ }^{26}$

We conducted meta-regression to explore the impact of studies with high versus low risk of bias for each risk of bias criterion. For the network meta-regression, the no treatment or placebo group was the referent, and we assumed that effect modification differed between comparisons. If risk of bias influenced results, we included only low risk of bias studies in generating best estimates. To explore the impact of enteral nutrition and mechanical ventilation, we conducted metaregression using the proportion of patients with enteral nutrition or mechanical ventilation as the independent variable. We performed subgroup analysis comparing results in studies that specified inclusion of critically ill patients with risk factors for gastrointestinal bleeding versus studies that did not mention risk factors in their inclusion criteria.

When networks are sparse, random-effects models may generate implausibly wide credible intervals from network meta-analysis estimates, even when the direct and indirect estimates are coherent. When this occurred, we either conducted a fixed-effect network meta-analysis or used the direct estimates as our best estimates of the treatment effects. ${ }^{27}{ }^{28}$ All network meta-analyses were performed using the gemtc package of $R$ version 3.4.3 (R Core Team, Vienna, Austria), absolute effects in networks were calculated using WinBUGS version 1.4.3 (MRC Biostatistics Unit, Cambridge, UK), and networkplot command of Stata version 15.1 (StataCorp, College Station, Texas, USA) was used to draw the network plots. ${ }^{29}$

In networks with incoherence in many comparisons, we compared network estimates to direct and indirect 
estimates. When we found direct versus network estimates inconsistent and counterintuitive, we examined odds ratios and relative risks in both randomeffects and fixed-effect models, seeking an approach that provided plausible network estimates. When none of these approaches was satisfactory, we did not consider the network meta-analysis further for those outcomes and instead relied on direct paired comparisons as the best estimates of effect.

\section{Assessment of certainty of evidence}

The GRADE (Grading of Recommendations, Assessment, Development, and Evaluation) approach informed the assessment of certainty of evidence for each outcome (box 2), ${ }^{31-33}$ including certainty ratings from the direct comparisons in our pairwise metaanalyses, ${ }^{3034-38}$ and certainty of evidence in network meta-analyses. ${ }^{31} 33$ Certainty ratings of indirect estimates started at the lowest ratings of the direct comparisons that contributed to the most-dominant first order loop with further rating down, when necessary, for intransitivity. Ratings of the certainty of estimates for direct and indirect estimates to inform the rating of network estimates included risk of bias, inconsistency, indirectness and publication bias, while imprecision was assessed at the network level. We judged imprecision by comparing the confidence intervals or credible intervals to decision thresholds ${ }^{34}$ chosen by the guideline panel. For the certainty of network estimates, we started with the estimate-direct or indirect-that dominated the network estimate, or used the higher of the direct and indirect estimates if they both contributed importantly to the network estimate. If incoherence was present, we rated down the certainty of the network estimates and used the estimate-direct or indirect-with the higher certainty evidence as the best estimate of treatment effect. We used the MAGICapp platform to develop the GRADE summary of finding tables.

\section{Results}

\section{Description of included studies}

Figure 1 shows the details of study selection process. We identified 479 records from our updated literature search and 13 potentially eligible studies from relevant reviews. After title and abstract screening, we assessed 70 full text articles, of which 18 proved eligible. Including 54 trials from our previous network meta-analysis (populations from three trials identified

Box 2: Certainty of evidence and definitions ${ }^{30}$

- High certainty-We are very confident that the true effect lies close to that of the estimate of the effect

- Moderate certainty-We are moderately confident in the effect estimate. The true effect is likely to be close to the estimate of the effect, but there is a possibility that it is substantially different

- Low certainty-Our confidence in the effect estimate is limited. The true effect may be substantially different from the estimate of the effect

- Very low certainty-We have very little confidence in the effect estimate. The true effect is likely to be substantially different from the estimate of effect from previous network meta-analysis did not meet our eligibility criteria), we ultimately included 72 trials.

These 72 randomised controlled trials, with sample sizes from 22 to 3298, enrolled a total of 12660 patients. Figure 2 presents the network plot including all outcomes and demonstrates that the most common comparisons were between H2RAs and placebo or no prophylaxis, followed by H2RAs versus sucralfate and PPIs versus H2RAs.

Fifty trials included critically ill patients with risk factors for gastrointestinal bleeding (appendix 2 summarises the risk factors listed), and 22 trials specified inclusion only of critically ill patients. Sixty five trials included patients in intensive care, two trials were of neurosurgery patients, one trial was of patients with fulminant hepatic failure, one trial of patients from three wards (department of intensive care, neurosurgery, and plastic surgery), and three trials of critically ill patients without further specification (appendix 3).

\section{Risk of bias}

Appendix 4 summarises risk of bias assessment that identified the main limitations as possible lack of allocation sequence concealment (54.2\%), lack of blinding (62.5\%), and excessive loss to follow-up $(23.6 \%)$.

\section{Outcomes}

Appendix 5 presents network plots for each outcome. Tests of incoherence raised no concerns for mortality, pneumonia, $C$ difficile infection, length of intensive care stay, length of hospital stay, and duration of mechanical ventilation. For clinically important gastrointestinal bleeding and overt bleeding, we found incoherence for comparisons of drugs with one another and no treatment and found counterintuitive results in each of the models we explored (appendix 6). Counterintuitive results included credible intervals for direct estimates from the network far (and implausibly) wider than confidence intervals for the direct estimates from the conventional paired metaanalysis; credible intervals for network estimates far and implausibly wider than the credible intervals for the direct comparisons; and network point estimates not being between the direct and indirect estimates. We therefore focused on results from direct pairwise meta-analysis rather than from network meta-analysis for clinically important gastrointestinal bleeding and overt bleeding, but used network meta-analysis results for all other outcomes. Appendix 7 presents SUCRA ranking of interventions for each outcome.

\section{Mortality}

Network meta-analysis estimates from 51 trials including 10277 patients $^{11} 1214$ 39-87 demonstrated odds ratios for all comparisons close to 1.0 with moderate or very low certainty (table 1 of appendix 8 ). PPIs probably have no impact on mortality compared with placebo or no prophylaxis (odds ratio 1.06 (95\% credible interval 0.90 to 1.28 ), 13 more per 1000 


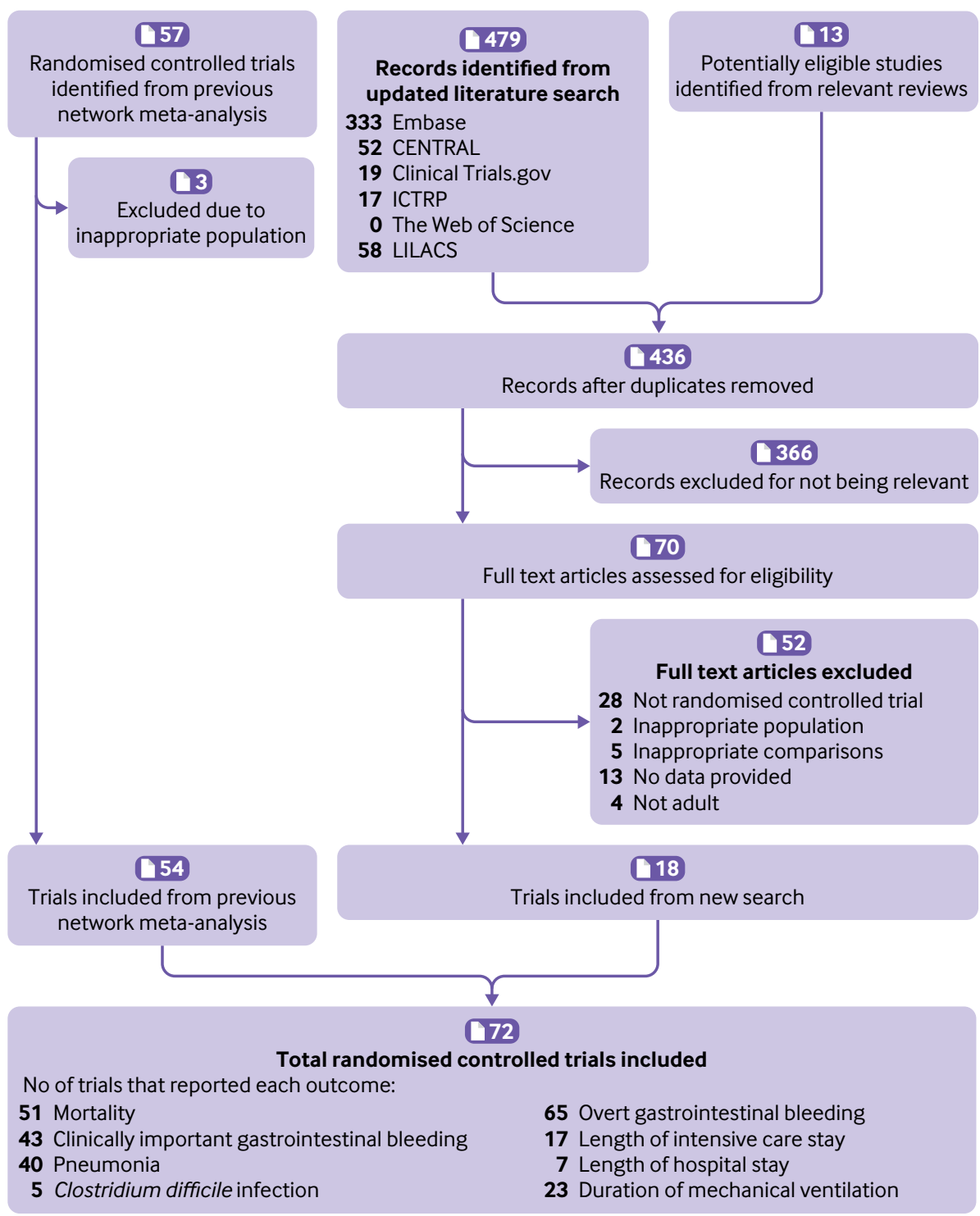

Fig 1 | PRISMA flow diagram of studies included in review of gastrointestinal bleeding prophylaxis

patients, moderate certainty, table 1 of appendix 8), and neither do H2RAs (0.96 (0.79 to 1.19), 9 fewer per 1000 patients, moderate certainty, table 1 of appendix 8). Network meta-regression suggested similar results in high and low risk of bias studies for mortality, and we therefore present results for all trials (appendix 9). The SUP-ICU trial reported a possible subgroup effect suggesting that PPIs relative to placebo may increase mortality in the sickest patients, ${ }^{14}$ but the credibility of this subgroup effect is low (most important reasons for low credibility: the subgroup hypothesis and the direction of the subgroup effect are not specified a priori). ${ }^{88}$

\section{Clinically important gastrointestinal bleeding}

Forty three trials including 10096 patients ${ }^{11-144144-47} 49$ 52-58 6061 63-65 67 69 73 74 76 78-83 85-87 89-96 reported clinically important gastrointestinal bleeding. Subgroup analysis based on each risk of bias criterion (concealment and blinding were highly correlated, so they were combined into one variable) showed that studies that failed to conceal or blind reported larger effect for PPIs versus H2RAs and smaller effect for H2RAs versus sucralfate (table 1 and appendix 10); for these comparisons, we focused on low risk of bias results.

We grouped patients into four categories according to risk of clinically important gastrointestinal bleeding: low risk (<2\%), moderate risk (2-4\%), high risk $(>4-8 \%)$, and highest risk (>8\%) (appendix 11), and calculated absolute effects for each category for clinically important gastrointestinal bleeding and overt bleeding.

Results demonstrated that, for patients at highest or high risk of bleeding, both PPIs and H2RAs probably reduce the risk of clinically important gastrointestinal bleeding compared with placebo or no prophylaxis. For PPIs the odds ratio was 0.61 (95\% confidence interval 0.42 to 0.89 ), 33 fewer per 1000 for highest risk and 23 fewer for high risk patients, moderate certainty (table 2 and fig 3). For H2RAs the odds ratio was 0.46 (0.27 to 


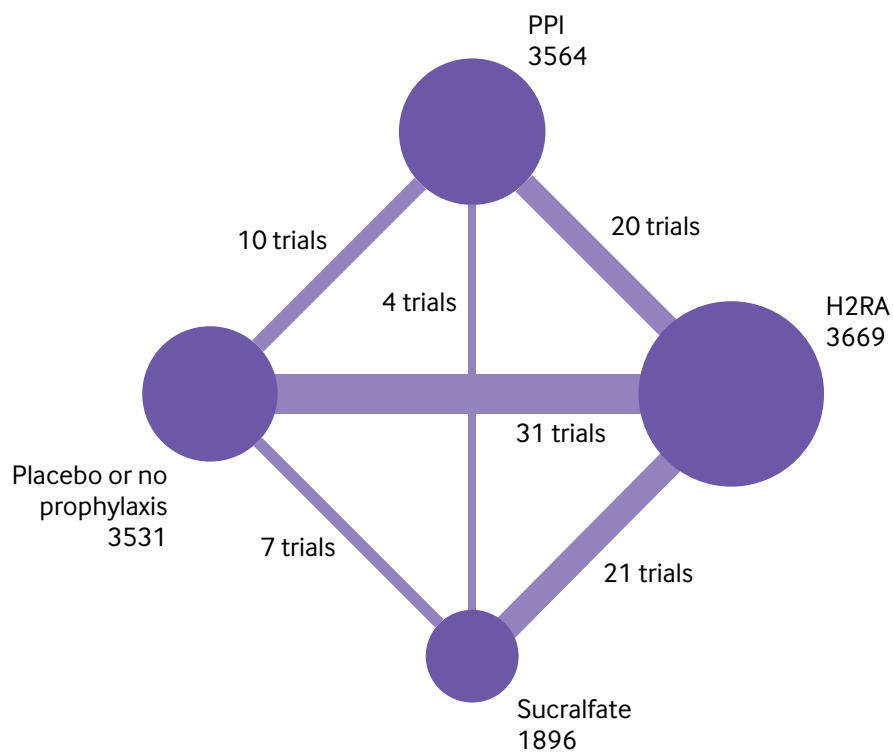

Fig 2 | Network plot of comparisons among proton pump inhibitors (PPIs), histamine-2 receptor antagonists (H2RAs), sucralfate, or no gastrointestinal bleeding prophylaxis

0.79), 46 fewer per 1000 for highest risk and 31 fewer for high risk patients, moderate certainty (table 2 and fig 4). For patients at lower risk, the absolute effects were considerably smaller (table 2). PPIs possibly reduce clinically important gastrointestinal bleeding relative to H2RAs, but the confidence intervals were wide and included a benefit of $\mathrm{H} 2 \mathrm{RAs}$ (odds ratio 0.58 (0.29 to 1.17), table 2 and fig 5). H2RAs compared with sucralfate probably reduce clinically important gastrointestinal bleeding (odds ratio 0.46 (0.23 to 0.91), moderate certainty for higher risk groups, table 2). Evidence regarding sucralfate versus PPIs and placebo was essentially uninformative with very wide confidence intervals (table 2). Both subgroup analysis within the SUP-ICU trial and between trials metaregression provided no support for the hypothesis that enteral nutrition influenced the relative impact of interventions (appendix 9 presents results for metaregression and subgroup analysis).

\section{Pneumonia}

Forty trials including 9288 patients $^{11} 14$ 39-41 44-48 53 54-56 $57596163-67697173757679-83 \quad 85$ 90-95 97-99

reported

\begin{tabular}{|c|c|c|c|}
\hline Comparison & Low risk of bias result & High risk of bias result* & $\begin{array}{l}\text { Subgroup difference } \\
\text { (P value) }\end{array}$ \\
\hline PPIs $v$ placebo & $0.62(0.42$ to 0.90$)$ & $0.33(0.01$ to 8.21$)$ & 0.70 \\
\hline H2RAs $v$ placebo & $0.43(0.18$ to 1.01$)$ & $0.54(0.26$ to 1.10$)$ & 0.69 \\
\hline Sucralfate $v$ placebo & $3.36(0.34$ to 33.13$)$ & $0.63(0.28$ to 1.41$)$ & 0.18 \\
\hline PPIs $v$ H2RAs & $0.58(0.29$ to 1.17$)$ & $0.20(0.07$ to 0.54$)$ & $0.08+$ \\
\hline PPIs $v$ sucralfate & $0.31(0.03$ to 3.05$)$ & $0.27(0.01$ to 6.93$)$ & 0.95 \\
\hline H2RAs v sucralfate & $0.46(0.23$ to 0.91$)$ & $1.18(0.66$ to 2.14$)$ & $0.04 t$ \\
\hline
\end{tabular}

pneumonia. PPIs may increase the risk of pneumonia compared with placebo or no prophylaxis (odds ratio 1.39 (95\% credible interval 0.98 to 2.10 ), 50 more per 1000 patients, low certainty, table 3), as may H2RAs (1.26 (0.89 to 1.85$), 34$ more per 1000 patients, low certainty, table 3$)$. PPIs may increase the risk of pneumonia compared with sucralfate (1.63 (1.12 to 2.46), 70 more per 1000 patients, low certainty, table 3), as may H2RAs (1.47 (1.11 to 2.03), 53 more per 1000 patients, low certainty, table 3). Network metaregression suggested similar results in high and low risk of bias studies for pneumonia (appendix 9).

\section{Clostridium difficile infection}

Five trials including 3849 patients ${ }^{11} 12148096$ reported $C$ difficile infection, of which four compared PPI with placebo or no prophylaxis and one compared PPI with H2RA. $C$ difficile infection was rare (baseline risk of $1.5 \%$ ), and the absolute effect of any intervention would therefore be very small (for example, for PPIs versus placebo the odds ratio was 0.82 ( $95 \%$ credible interval 0.31 to 2.47), 3 fewer per 1000 patients, moderate certainty, see table 2 of appendix 8). Credible intervals around odds ratios were very wide, and results were therefore essentially uninformative (table 2 of appendix 8). Network meta-regression suggested similar results in high and low risk of bias studies for $C$ difficile infection (appendix 9).

\section{Overt gastrointestinal bleeding}

Overt gastrointestinal bleeding is bleeding without the consequences of clinically important gastrointestinal bleeding such as haemodynamic changes, transfusion, haemoglobin decrease, or need for surgery. Sixty five trials including 11662 patients $^{11-14} 39$ 41-50 52-58 60-69 71-83 85-87 89-96 98-107 reported on overt bleeding. Subgroup analysis showed that concealment or blinding (the combined variable) influenced results for the comparisons of PPIs versus placebo and H2RAs versus sucralfate, and missing outcome data influenced results for PPIs versus placebo (table 4 and appendix 10). We therefore used low risk of bias results for these two comparisons. PPIs reduce overt bleeding relative to placebo (odds ratio 0.59 ( $95 \%$ confidence interval 0.45 to 0.76 ), high certainty, table 3 of appendix 8). This is probably also true for H2RAs versus placebo (odds ratio $0.38,(0.24$ to 0.59 ), moderate certainty, table 3 of appendix 8). Sucralfate possibly reduces overt bleeding relative to placebo, but the confidence interval includes increased bleeding (odds ratio 0.58 (0.30 to 1.11 ), moderate certainty, table 3 of appendix 8). PPIs reduce overt bleeding relative to H2RAs (odds ratio 0.43 (0.25 to 0.74 ), high certainty, table 3 of appendix 8).

Meta-regression suggested the possibility that H2RAs versus placebo had a smaller relative effect when patients received enteral nutrition, but the credibility of this subgroup effect is low (most important reason for low credibility: the effect is suggested by comparisons between studies) (appendix 9). ${ }^{88}$ Similarly, subgroup analysis suggested the 


\begin{tabular}{|c|c|c|c|c|c|c|c|}
\hline Comparison & $\begin{array}{l}\text { Odds ratio }(95 \% \mathrm{Cl}) \\
\text { and measurements }\end{array}$ & $\begin{array}{r}A \\
\text { estin }\end{array}$ & $\begin{array}{l}\text { solute effect } \\
\text { lates (per } 100\end{array}$ & & $\begin{array}{l}\text { Absolute difference } \\
(95 \% \mathrm{Cl}) \text { per } 1000\end{array}$ & $\begin{array}{l}\text { Certainty in } \\
\text { effect } \\
\text { estimates }\end{array}$ & Plain text summary \\
\hline \multirow[t]{4}{*}{$\begin{array}{l}\text { PPIs } v \\
\text { placebo }\end{array}$} & \multirow{4}{*}{$\begin{array}{l}0.61(0.42 \text { to } 0.89) \\
4317 \text { patients in } 8 \\
\text { studies }\end{array}$} & Low risk & Placebo: 12 & PPIs: 7 & $-5(-7$ to -1$)$ & Moderate* $^{\star}$ & $\begin{array}{l}\text { PPIs probably reduce CIB by less than the amount most } \\
\text { people would need to choose a PPI }\end{array}$ \\
\hline & & Moderate risk & 30 & 19 & $-11(-17$ to -3$)$ & Low $^{*}+$ & $\begin{array}{l}\text { PPIs may reduce CIB by less than the amount most } \\
\text { people would need to choose a PPI }\end{array}$ \\
\hline & & High risk & 60 & 37 & $-23(-34$ to -6$)$ & Moderatet & PPIs probably reduce CIB \\
\hline & & Highest risk & 90 & 57 & $-33(-50$ to -9$)$ & Moderatet & PPIs probably reduce CIB \\
\hline \multirow[t]{4}{*}{$\begin{array}{l}\text { H2RAs } V \\
\text { placebo }\end{array}$} & \multirow{4}{*}{$\begin{array}{l}0.46(0.27 \text { to } 0.79) \\
1242 \text { patients in } 14 \\
\text { studies }\end{array}$} & Low risk & Placebo: 12 & H2RAs: 6 & $-6(-9$ to -2$)$ & Moderate* $^{*}$ & $\begin{array}{l}\text { H2RAs probably reduce CIB by less than the amount } \\
\text { most people would need to choose a H2RA }\end{array}$ \\
\hline & & Moderate risk & 30 & 14 & $-16(-22$ to -6$)$ & Low $^{*}+$ & $\begin{array}{l}\text { H2RAs may reduce CIB by less than the amount most } \\
\text { people would need to choose a H2RA }\end{array}$ \\
\hline & & High risk & 60 & 29 & $-31(-43$ to -12$)$ & Moderatet & H2RAs probably reduce CIB \\
\hline & & Highest risk & 90 & 44 & $-46(-64$ to -18$)$ & Moderatet & H2RAs probably reduce CIB \\
\hline \multirow{4}{*}{$\begin{array}{l}\text { Sucralfate } v \\
\text { placebo }\end{array}$} & \multirow{4}{*}{$\begin{array}{l}0.76(0.36 \text { to } 1.62) \\
874 \text { patients in } 6 \\
\text { studies }\end{array}$} & Low risk & Placebo: 12 & Suc: 9 & $-3(-8$ to 7$)$ & Moderate $^{\star}$ & Sucralfate probably does not have an important effect \\
\hline & & Moderate risk & 30 & 23 & $-7(-19$ to 18$)$ & Low $^{\star}+$ & Sucralfate may not have an important effect \\
\hline & & High risk & 60 & 46 & $-14(-38$ to 34$)$ & Low $\neq$ & Sucralfate may not have an important effect \\
\hline & & Highest risk & 90 & 70 & $-20(-56$ to 48$)$ & Low & Sucralfate may not have an important effect \\
\hline \multirow{4}{*}{$\begin{array}{l}\text { PPIs V } \\
\text { H2RAs }\end{array}$} & \multirow{4}{*}{$\begin{array}{l}0.58 \text { (0.29 to } 1.17) \text {. } \\
1010 \text { patients in } 5 \\
\text { studies with low risk } \\
\text { of bias }\end{array}$} & Low risk & H2RAs: 12 & PPIs: $7 \S$ & $-5(-17$ to 1$)$ & Low $^{\star}+$ & There may be no important difference \\
\hline & & Moderate risk & 32 & $19 \S$ & $-13(-44$ to 3$)$ & Low ${ }^{\star} \dagger$ & PPIs may reduce $\mathrm{CIB}$ more than $\mathrm{H} 2 \mathrm{RAs}$ \\
\hline & & High risk & 62 & $37 \S$ & $-25(-80$ to 5$)$ & Moderatet & PPIs probably reduce $\mathrm{CIB}$ more than $\mathrm{H} 2 \mathrm{RAs}$ \\
\hline & & Highest risk & 94 & $57 \S$ & $-37(-116$ to 8$)$ & Moderatet & PPIs probably reduce $\mathrm{CIB}$ more than $\mathrm{H} 2 \mathrm{RAs}$ \\
\hline \multirow[t]{4}{*}{$\begin{array}{l}\text { PPIs } v \\
\text { sucralfate }\end{array}$} & \multirow{4}{*}{$\begin{array}{l}0.30(0.05 \text { to } 1.92) \\
211 \text { patients in } 2 \\
\text { studies }\end{array}$} & Low risk & Suc: 23 & PPIs: 7§ & $-16(-117$ to 3$)$ & Very low* $\neq$ & $\begin{array}{l}\text { Whether there is an important difference or not is very } \\
\text { uncertain }\end{array}$ \\
\hline & & Moderate risk & 61 & $19 \S$ & $-42(-260$ to 9$)$ & Very low ${ }^{\star} \ddagger$ & $\begin{array}{l}\text { Whether there is an important difference or not is very } \\
\text { uncertain }\end{array}$ \\
\hline & & High risk & 113 & $37 \S$ & $-76(-398$ to 17$)$ & Low & PPIs may reduce CIB compared with sucralfate \\
\hline & & Highest risk & 168 & $57 \S$ & $-111(-490$ to 27$)$ & Low $\ddagger$ & PPIs may reduce CIB compared with sucralfate \\
\hline \multirow{4}{*}{$\begin{array}{l}\text { H2RAs } V \\
\text { sucralfate }\end{array}$} & \multirow{4}{*}{$\begin{array}{l}0.46 \text { (0.23 to } 0.91) \text {. } \\
1340 \text { patients in } 2 \\
\text { studies with low risk } \\
\text { of bias }\end{array}$} & Low risk & Suc: 13 & H2RAs: 61 & $-7(-20$ to -1$)$ & Low $^{*} \dagger$ & There may be no important difference \\
\hline & & Moderate risk & 30 & 149 & $-16(-44$ to -1$)$ & Low ${ }^{*}+$ & H2RAs may reduce CIB compared with sucralfate \\
\hline & & High risk & 61 & 299 & $-32(-86$ to -3$)$ & Moderatet & H2RAs probably reduce CIB compared with sucralfate \\
\hline & & Highest risk & 91 & 449 & $-47(-123$ to -4$)$ & Moderatet & H2RAs probably reduce CIB compared with sucralfate \\
\hline \multicolumn{8}{|c|}{$\begin{array}{l}\text { PPIs = proton pump inhibitors; H2RAs = histamine- } 2 \text { receptor antagonists. } \\
\text { *Rated down due to uncertainty in baseline risk for some risk factors. } \\
\text { tRated down for imprecision. } \\
\text { †Rated down } 2 \text { levels for imprecision. }\end{array}$} \\
\hline
\end{tabular}

possibility that PPIs versus placebo had a smaller effect in studies that specified that patient had risk factors for bleeding than those that did not mention risk factors in their inclusion criteria, but once again the credibility of this subgroup effect is low (most important reasons for low credibility: the effect is suggested by comparisons

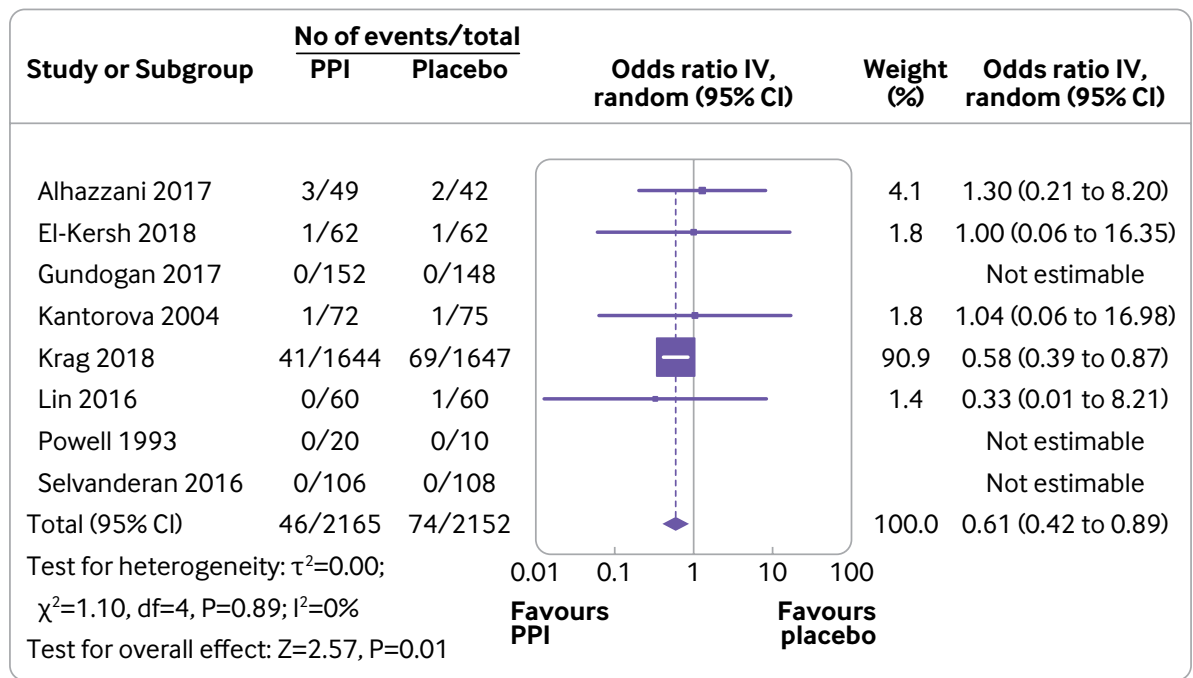

Fig 3 | Forest plot for proton pump inhibitors (PPIs) versus placebo for clinically important gastrointestinal bleeding 


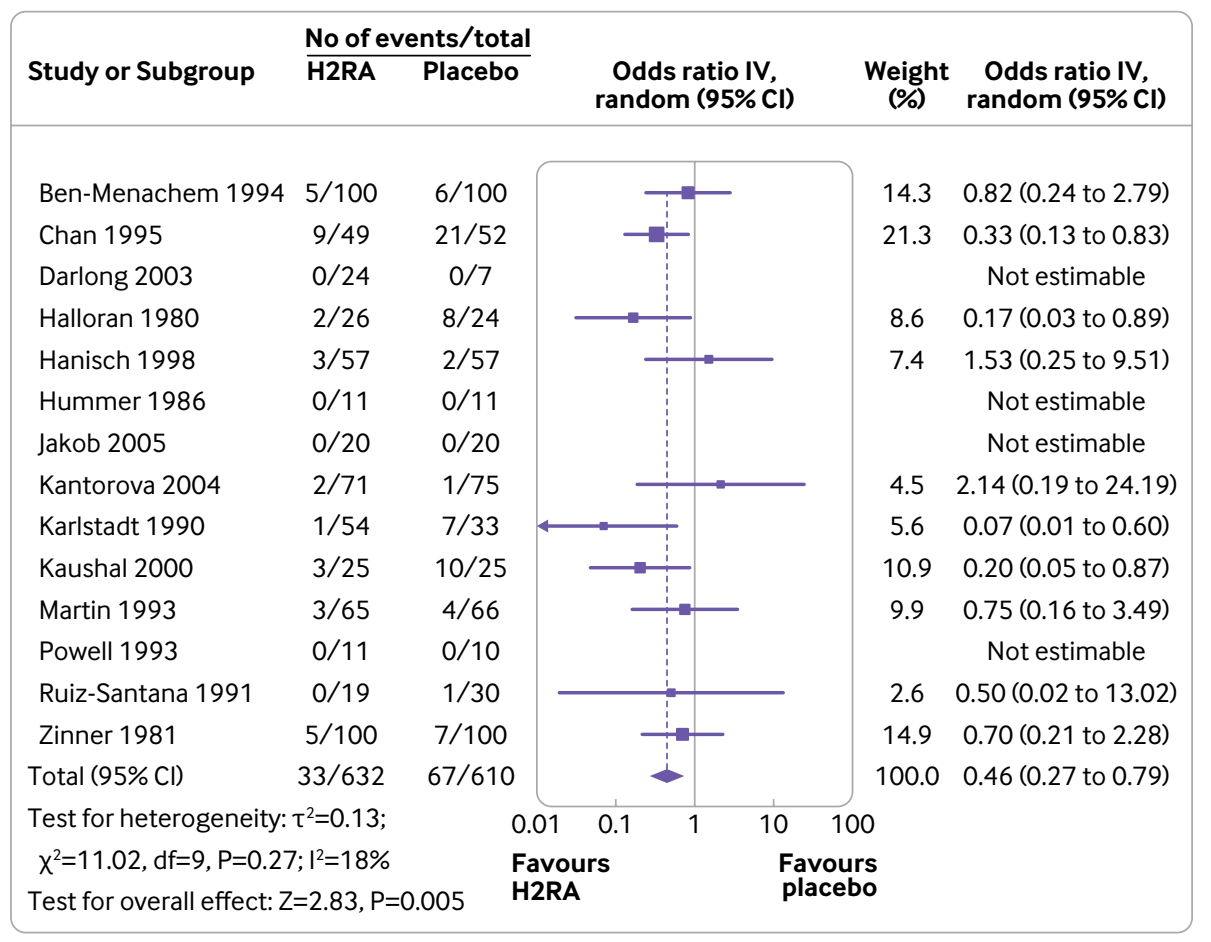

Fig 4 | Forest plot for histamine-2 receptor antagonists (H2RAs) versus placebo for clinically important gastrointestinal bleeding

between studies, and the subgroup hypothesis and the direction of the subgroup effect are not specified a priori) (appendix 9).88

Length of intensive care stay and length of hospital stay

Seventeen trials including 3533 patients $^{11} 1246475156$ $60636471737780-82879096$ reported length of stay in in tensive care, and seven trials including 831 patients ${ }^{11} 124059738095$ reported length of hospital stay. Results suggested no important difference between any of interventions (tables 4 and 5 of appendix 8). Network meta-regression suggested similar results in high and low risk of bias studies on results (appendix 9).
Duration of mechanical ventilation

Twenty three trials including 3625 patients $^{11} 12$ 394143465354565961646571737879818285919596 reported duration of mechanical ventilation or duration of intubation. Results suggested no important difference between any of interventions in terms of duration of mechanical ventilation or duration of intubation (table 6 of appendix 8). Network meta-regression suggested similar results in high and low risk of bias studies for duration of mechanical ventilation (appendix 9).

\section{Discussion}

We found moderate certainty evidence that neither PPIs nor H2RAs affect mortality compared with no prophylaxis (table 1 of appendix 8). We found lower

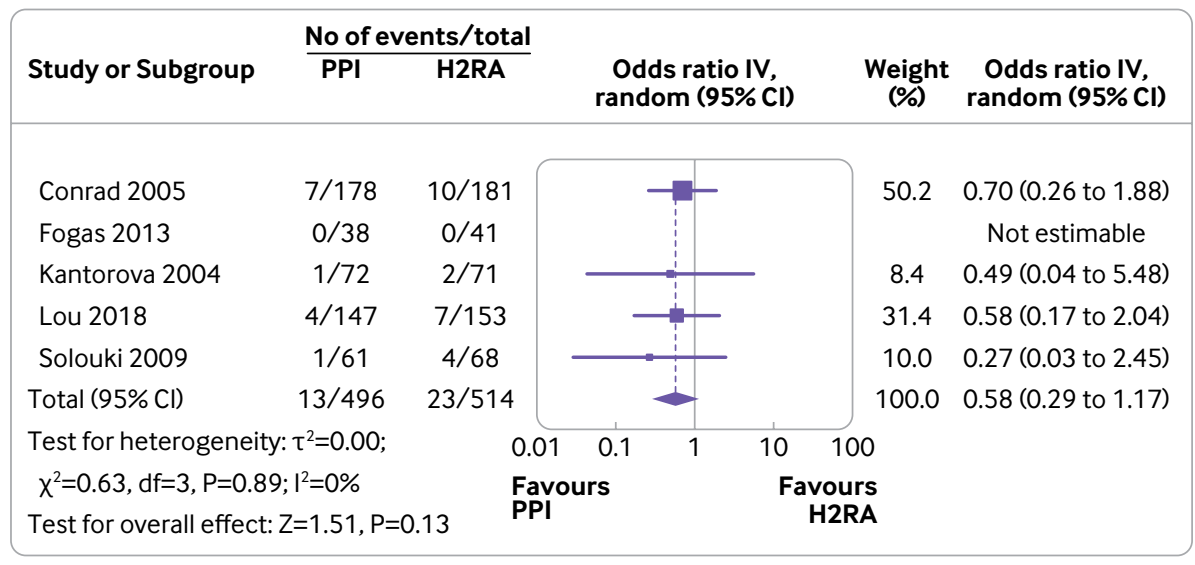

Fig 5 | Forest plot for proton pump inhibitors (PPIs) versus histamine-2 receptor antagonists (H2RAs) for clinically important gastrointestinal bleeding with low risk of bias studies 


\begin{tabular}{|c|c|c|c|c|c|}
\hline Comparison & $\begin{array}{l}\text { Direct estimate } \\
(95 \% \mathrm{Crl}) ; \text { Certainty } \\
\text { of evidence }\end{array}$ & $\begin{array}{l}\text { Indirect estimate ( } 95 \% \\
\mathrm{Crl}) ; \text { Certainty of evidence }\end{array}$ & $\begin{array}{l}\text { Network estimate } \\
\text { ( } 95 \% \text { Crl); Certainty } \\
\text { of evidence* }\end{array}$ & \multicolumn{2}{|c|}{ Absolute effect estimatest ( $95 \%$ Crl) per 1000} \\
\hline \multirow[t]{2}{*}{ PPIs $v$ placebo } & \multirow{2}{*}{$\begin{array}{l}1.08(0.77 \text { to } 1.74) ; \\
\text { Moderate } \neq\end{array}$} & \multirow{2}{*}{$\begin{array}{l}1.78 \text { (0.98 to } 3.23) ; \\
\text { Moderate } \neq\end{array}$} & \multirow{2}{*}{$\begin{array}{l}1.39 \text { (0.98 to 2.10); } \\
\text { Low } \ddagger \S 9\end{array}$} & Placebo: 162 & PPIs: 212 (159 to 287) \\
\hline & & & & Difference: 50 (-3 to 125$)$ & \\
\hline \multirow[t]{2}{*}{ H2RAs $v$ placebo } & \multirow{2}{*}{$\begin{array}{l}1.32(0.87 \text { to } 2.02) ; \\
\text { Moderate } \neq\end{array}$} & \multirow{2}{*}{$\begin{array}{l}0.91(0.50 \text { to } 1.94) ; \\
\text { Moderate } \neq\end{array}$} & \multirow{2}{*}{$\begin{array}{l}1.26 \text { (0.89 to } 1.85) ; \\
\text { Low‡§9 }\end{array}$} & Placebo: 162 & H2RAs: 196 (148 to 263) \\
\hline & & & & Difference: 34 (-14 to 101$)$ & \\
\hline \multirow[t]{2}{*}{ Sucralfate $v$ placebo } & \multirow{2}{*}{$\begin{array}{l}2.13(0.69 \text { to } 6.74) ; \\
\text { Moderate } \neq\end{array}$} & \multirow{2}{*}{$\begin{array}{l}0.68(0.42 \text { to } 1.11) \\
\text { Moderate } \neq\end{array}$} & \multirow{2}{*}{$\begin{array}{l}0.85 \text { (0.56 to } 1.33) ; \\
\text { Low } \neq \S\end{array}$} & Placebo: 162 & Sucralfate: 142 (98 to 204 ) \\
\hline & & & & Difference: -20 (-64 to 42$)$ & \\
\hline \multirow[t]{2}{*}{ PPIs $v$ H2RAs } & \multirow{2}{*}{$\begin{array}{l}1.10(0.79 \text { to } 1.51) ; \\
\text { Moderate } \neq\end{array}$} & \multirow{2}{*}{$\begin{array}{l}1.03(0.57 \text { to } 1.95) ; \\
\text { Moderate } \neq\end{array}$} & \multirow{2}{*}{$\begin{array}{l}1.11(0.82 \text { to } 1.50) ; \\
\text { Low } \neq \S\end{array}$} & H2RAs: 196 (148 to 263) & PPIs: 212 (159 to 287) \\
\hline & & & & Difference: 16 (-32 to 68$)$ & \\
\hline \multirow[t]{2}{*}{ PPIs $v$ sucralfate } & \multirow{2}{*}{$\begin{array}{l}2.89 \text { (1.38 to } 6.00) ; \\
\text { Moderate } \neq\end{array}$} & \multirow{2}{*}{$\begin{array}{l}1.27 \text { (0.84 to 2.04); } \\
\text { Moderate } \neq\end{array}$} & \multirow{2}{*}{$\begin{array}{l}1.63(1.12 \text { to } 2.46) ; \\
\text { Low } \ddagger\end{array}$} & Sucralfate: 142 (98 to 204$)$ & PPIs: 212 (159 to 287) \\
\hline & & & & Difference: 70 (18 to 131) & \\
\hline \multirow[t]{2}{*}{ H2RAs v sucralfate } & \multirow{2}{*}{$\begin{array}{l}1.34 \text { (1.04 to } 1.82) ; \\
\text { Moderate } \neq\end{array}$} & \multirow{2}{*}{$\begin{array}{l}2.77(0.90 \text { to } 8.24) ; \\
\text { Moderate } \neq\end{array}$} & \multirow{2}{*}{$\begin{array}{l}1.47(1.11 \text { to } 2.03) ; \\
\text { Low } \neq \S\end{array}$} & Sucralfate: 142 (98 to 204) & H2RAs: 196 (148 to 263) \\
\hline & & & & Difference: 53 (15 to 99) & \\
\hline \multicolumn{6}{|c|}{$\begin{array}{l}\mathrm{Crl}=\text { credible interval; PPIs = proton pump inhibitors; } \mathrm{H} 2 \mathrm{RAs}=\text { histamine- } 2 \text { receptor antagonists. } \\
\text { *Higher of direct or indirect confidence (without consider imprecision), and then considered imprecision and incoherence. } \\
\text { tWe used as baseline risk in the placebo group of the SUP-ICU trial. } \\
\text { †Rated down for risk of bias. } \\
\text { §Rated down for imprecision. } \\
\text { TWe are skeptical of the result because the pooled result including smaller studies conflicts with the evidence from the larg }\end{array}$} \\
\hline
\end{tabular}

certainty evidence of no impact on mortality for other comparisons (table 1 of appendix 8).

We found moderate or low certainty evidence that PPIs and H2RAs probably reduce clinically important gastrointestinal bleeding relative to no prophylaxis (table 2) and high or moderate certainty evidence that both drugs reduce overt gastrointestinal bleeding relative to no prophylaxis (table 3 of appendix 8). For higher risk patients, the impact on clinically important gastrointestinal bleeding may be important (PPIs absolute difference for highest risk patients 3.3\%, for high risk patients 2.3\%; H2RAs for highest risk patients $4.6 \%$, for high risk patients $3.1 \%$; table 2 ); this may not be true for lower risk patients (table 2). PPIs relative to H2RAs possibly reduce clinically important gastrointestinal bleeding, but the confidence interval included superiority of H2RAs (odds ratio 0.58 (95\% confidence interval 0.29 to 1.17), table 2 and fig 5). Sucralfate may not reduce clinically important gastrointestinal bleeding (table 2).

PPIs and H2RAs may increase the risk of pneumonia (absolute increases 5.0\% and 3.4\% respectively, table 3). $C$ difficile infection occurred infrequently, resulting in very wide credible intervals around odds ratios that were essentially uninformative. However, because $C$ difficile infection was rare, even the largest plausible increase in risk will be small. Few trials reported on other adverse effects. Prophylaxis may have no impact on length of intensive care stay, length of hospital stay, or duration of mechanical ventilation.

\section{Strength and limitations of study}

Strengths of this review include a comprehensive search to identify eligible trials; independent study selection, data extraction, and risk of bias assessment by two reviewers; focus on low risk of bias studies when low and high risk of bias studies yielded differing results; and application of the GRADE approach to rate the certainty of evidence. We also presented absolute effects for all comparisons and outcomes and for patients at different risk of gastrointestinal bleeding.
Finally, rather than mechanically reporting network meta-analysis results, we also considered whether they might be misleading. It is probably inadvisable to conduct network meta-analysis when direct and indirect estimates differ considerably throughout the network (that is, incoherence).$^{28}$ We found this problem for both clinically important gastrointestinal bleeding and overt bleeding and, probably as a result, found network meta-analysis estimates that were inconsistent with direct estimates and counterintuitive. Testing different measures of effect or model assumptions did not resolve the issue. Therefore, for these two outcomes, we relied on direct comparisons only.

Limitations include clinical heterogeneity across eligible trials that enrolled different populations and often did not clearly identify the risk factors for bleeding in the participating individuals. However, most patients in most trials received mechanical ventilation, an indication for prophylaxis in most intensive care units worldwide. Definitions of clinically important gastrointestinal bleeding and overt bleeding differed; most, however, adhered to standard criteria. Most trials did not report the duration of follow-up.

Some results proved logically inconsistent. For instance, in comparisons against placebo or no prophylaxis, results showed larger effects with H2RAs than with PPIs on reduction in clinically important gastrointestinal bleeding. Direct comparisons of the two agents, however, raised the possibility that PPIs result in larger reductions in clinically important gastrointestinal bleeding than do H2RAs.

Enteral nutrition may provide protection against gastrointestinalbleeding, and the impact of prophylaxis in patients receiving enteral nutrition may therefore be small, at least in patients at otherwise lower risk. It is also possible that enteral nutrition decreases the relative effect of prophylaxis on bleeding. Although meta-regression results suggested H2RAs had smaller relative effect on overt bleeding when patients received enteral nutrition, this subgroup effect proved of low credibility (appendix 9). ${ }^{88}$ We also identified a possible 
Table 4 | Low risk versus high risk of bias results (odds ratios (95\% confidence intervals)) for overt gastrointestinal bleeding

\begin{tabular}{llll} 
Comparison & Low risk of bias result & High risk of bias result* & $\begin{array}{l}\text { Subgroup difference } \\
\text { (P value) }\end{array}$ \\
\hline PPIs $v$ placebo & $0.59(0.45$ to 0.76$)$ & $0.20(0.09$ to 0.48$)$ & $0.02 \dagger$ \\
\hline H2RAs $v$ placebo & $0.34(0.19$ to 0.61$)$ & $0.45(0.23$ to 0.88$)$ & 0.54 \\
\hline Sucralfate $v$ placebo & $3.36(0.34$ to 33.13$)$ & $0.52(0.28$ to 0.95$)$ & 0.12 \\
\hline PPIs $v$ H2RAs & $0.57(0.27$ to 1.23$)$ & $0.32(0.16$ to 0.65$)$ & 0.28 \\
\hline PPIs $v$ sucralfate & $0.31(0.03$ to 3.05$)$ & $0.11(0.01$ to 2.20$)$ & 0.59 \\
\hline H2RAs $v$ sucralfate & $0.46(0.23$ to 0.91$)$ & $1.47(1.01$ to 2.15$)$ & $0.004 \dagger$ \\
\hline
\end{tabular}

*For PPIs versus placebo, studies were at high risk of bias if either allocation sequence concealment or blinding or missing outcome data were at high risk of bias. For other comparisons, studies were at high risk of bias if either allocation sequence concealment or blinding were at high risk of bias.

tImportant difference between low and high risk of bias result, so we used low risk of bias result as best estimate. influences mortality; that PPIs and H2RAs likely reduce bleeding; that reduction in bleeding is higher in patients with higher baseline risk of bleeding; and that resolving a number of issues, including the possibility that prophylactic agents increase the risk of pneumonia, will require additional randomised controlled trials. This review provides key evidence for the associated $B M J$ Rapid Recommendation, which uses additional context and methodology to produce recommendations for clinical practice.

\section{AUTHOR AFFILIATIONS}

${ }^{1}$ Department of Pharmacy, Beijing Chaoyang Hospital, Capital Medical University, Beijing, China

${ }^{2}$ Department of Health Research Methods, Evidence and Impact, McMaster University, Hamilton, Canada

subgroup effect for PPIs versus no prophylaxis: studies in which investigators specified that patients had risk factors had apparently smaller effects on overt bleeding than those in which there was no mention of risk factors. Once again, however, the apparent subgroup effect is of low credibility (appendix 9). ${ }^{88}$

\section{Relation to prior work}

Compared with previous, conventional pairwise metaanalysis, the use of indirect comparisons within this network meta-analysis adds additional information to the evidence regarding gastrointestinal bleeding prophylaxis, particularly with respect to establishing the impact of PPIs on gastrointestinal bleeding. Our review included more trials and substantially more patients: most importantly the SUP-ICU trial, ${ }^{14}$ which is both the largest trial to date addressing prophylaxis and at low risk of bias (the SUP-ICU trial concealed randomisation, blinded clinicians and study personnel, and lost very few patients to followup, and was thus at low risk of bias). In this review, we found that H2RAs likely reduce the risk of clinically important gastrointestinal bleeding compared with no prophylaxis and sucralfate; our previous network meta-analysis suggested no convincing impact of H2RAs. One consequence of this review's focus on studies at low risk of bias when results differed in high risk and low risk of bias studies was a confidence interval for the comparison of PPIs versus H2RAs on clinically important gastrointestinal bleeding wider than those in previous studies and including the possibility of benefit with H2RAs.

We found moderate certainty evidence that neither PPIs nor H2RAs reduce mortality relative to no prophylaxis. The SUP-ICU trial reported a possible subgroup effect suggesting PPIs may increase mortality in the sickest patients. Applying suggested criteria, however, demonstrated this possible subgroup effect is of low credibility (appendix 9). ${ }^{88}$

\section{Implications of study}

This systematic review provides important information for weighing the potential benefits and harms of alternative interventions for gastrointestinal bleeding prophylaxis in adult critically ill patients. Key messages include the likelihood that no intervention
${ }^{3}$ Evidence Based Social Science Research Center, School of Public Health, Lanzhou University, Lanzhou, China

${ }^{4}$ Department of Medicine, University of Toronto, Toronto, Canada

${ }^{5}$ Division of General Internal Medicine and Division of Clinical

${ }^{6}$ Institute of Health and Society, University of Oslo, Norway

${ }^{7}$ Department of Intensive Care, Copenhagen University Hospital Rigshospitalet, Copenhagen, Denmark

We thank members of the Rapid Recommendations panel for critical feedback on outcome selection, GRADE judgments, and manuscript feedback. We thank Karin Dearness for helping with developing search strategy. We thank Davide Papola, Stefan Schandelmaier, and Suzana Alves da Silva for helping with data extraction of some non-English studies. We thank Melanie Chiarot for helping us finding full texts for some studies.

Contributors: GHG, ZY, YW, and LL conceived the study. KD and ZY designed the search strategy, and KD performed the literature search. YW and XW screened studies for eligibility. XW, YW, Yingkai Wang, and ZM performed data extraction. YW, ZY, and GHG assessed the risk of bias. $L G, L H$, and $Y W$ performed data analysis. YW, RAS, LG, ZY, and GHG interpreted the data analysis and assessed the certainty of evidence. YW, LG, and ZY wrote the first draft of the manuscript, and all other authors revised the manuscript. GHG and LL are the guarantors. The corresponding author attests that all listed authors meet authorship criteria and that no others meeting the criteria have been omitted.

Funding: This systematic review is linked to a BMJ Rapid Recommendation, which was funded by the Digestive Medical Coordinated Development Center of Beijing Hospitals Authority. The funder did not play any role in the preparation and production of the systematic review.

Competing interests: All authors have completed the ICMJE uniform disclosure form at www.icmje.org/coi_disclosure.pdf and declare: no support from any organisation for the submitted work; no financial relationships with any organisations that might have an interest in the submitted work in the previous three years; AP and MHM are the co-authors of the SUP-ICU trial (doi:10.1056/NEJMoa1714919); GHG is one of the investigators of the REVISE trial. There are no other relationships or activities that could appear to have influenced the submitted work

Patient consent: Not required.

Ethical approval: Not required.

Data sharing: No additional data available.

Transparency: The manuscript's guarantors (GHG and LL) affirm that the manuscript is an honest, accurate, and transparent account of the study being reported; that no important aspects of the study have been omitted; and that any discrepancies from the study as planned (and, if relevant, registered) have been explained.

This manuscript not been deposited as a preprint.

This is an Open Access article distributed in accordance with the Creative Commons Attribution Non Commercial (CC BY-NC 4.0) license, which permits others to distribute, remix, adapt, build upon this work non-commercially, and license their derivative works on different terms, provided the original work is properly cited and the use is non-commercial. See: http://creativecommons.org/licenses/ by-nc/4.0/. Epidemiology, University Hospitals of Geneva, Geneva, Switzerland 
1 Cook DJ, Griffith LE, Walter SD, et al, Canadian Critical Care Trials Group. The attributable mortality and length of intensive care unit stay of clinically important gastrointestinal bleeding in critically ill patients. Crit Care 2001;5:368-75. doi:10.1186/cc1071

2 Barletta JF, Kanji S, MacLaren R, Lat I, Erstad BL, American-Canadian consortium for Intensive care Drug utilization (ACID) Investigators. Pharmacoepidemiology of stress ulcer prophylaxis in the United States and Canada. J Crit Care 2014;29:955-60. doi:10.1016/j. jcrc.2014.06.025

3 Krag M, Perner A, Wetterslev J, et al, SUP-ICU co-authors. Prevalence and outcome of gastrointestinal bleeding and use of acid suppressants in acutely ill adult intensive care patients. Intensive Care Med 2015;41:833-45. doi:10.1007/s00134-015-3725-1

4 Krag M, Perner A, Wetterslev J, et al, SUP-ICU Collaborators. Stress ulcer prophylaxis in the intensive care unit: an international survey of 97 units in 11 countries. Acta Anaesthesiol Scand 2015;59:576-85. doi:10.1111/aas.12508

5 Alhazzani W, Alshamsi F, Belley-Cote E, et al. Efficacy and safety of stress ulcer prophylaxis in critically ill patients: a network metaanalysis of randomized trials. Intensive Care Med 2018;44:1-11. doi:10.1007/s00134-017-5005-8

6 Alshamsi F, Belley-Cote E, Cook D, et al. Efficacy and safety of proton pump inhibitors for stress ulcer prophylaxis in critically ill patients: a systematic review and meta-analysis of randomized trials. Crit Care 2016;20:120. doi:10.1186/s13054-016-1305-6

7 Barbateskovic M, Marker S, Granholm A, et al. Stress ulcer prophylaxis with proton pump inhibitors or histamin-2 receptor antagonists in adult intensive care patients: a systematic review with meta-analysis and trial sequential analysis. Intensive Care Med 2019;45:143-58. doi:10.1007/s00134-019-05526-z

8 Huang HB, Jiang W, Wang CY, Qin HY, Du B. Stress ulcer prophylaxis in intensive care unit patients receiving enteral nutrition: a systematic review and meta-analysis. Crit Care 2018;22:20. doi:10.1186/ s13054-017-1937-1

9 Huang J, Cao Y, Liao C, Wu L, Gao F. Effect of histamine-2-receptor antagonists versus sucralfate on stress ulcer prophylaxis in mechanically ventilated patients: a meta-analysis of 10 randomized controlled trials. Crit Care 2010;14:R194. doi:10.1186/cc9312

10 Toews I, George AT, Peter JV, et al. Interventions for preventing upper gastrointestinal bleeding in people admitted to intensive care units. Cochrane Database Syst Rev 2018;6:CD008687. doi:10.1002/14651858.CD008687.pub2

11 Alhazzani W, Guyatt G, Alshahrani M, et al, Canadian Critical Care Trials Group. Withholding pantoprazole for stress ulcer prophylaxis in critically ill patients: a pilot randomized clinical trial and meta-analysis. Crit Care Med 2017;45:1121-9. doi:10.1097/ CCM.0000000000002461

12 El-Kersh K, Jalil B, McClave SA, et al. Enteral nutrition as stress ulcer prophylaxis in critically ill patients: A randomized controlled exploratory study. J Crit Care 2018;43:108-13. doi:10.1016/j. jcrc.2017.08.036

13 Gundogan K, Karakoc E, Teke T, et al. Effects of enteral nutrition on stress ulcer hemorrhage in critically ill patients: Multicenter randomized controlled trial. Intensive care medicine experimental 2017; 30th Annual Congress of the European Society of Intensive Care Medicine, ESICM 2017. Austria. 5 (2 supplement 1).

14 Krag M, Marker S, Perner A, et al, SUP-ICU trial group. Pantoprazole in patients at risk for gastrointestinal bleeding in the ICU. $N$ Engl J Med 2018;379:2199-208. doi:10.1056/NEJMoa1714919

15 Cook D, Guyatt G. Prophylaxis against upper gastrointestinal bleeding in hospitalized patients. N Engl J Med 2018;378:2506-16. doi:10.1056/NEJMra1605507

16 Buendgens L, Bruensing J, Matthes M, et al. Administration of proton pump inhibitors in critically ill medical patients is associated with increased risk of developing Clostridium difficile-associated diarrhea. J Crit Care 2014:29:696.e11-5. doi:10.1016/j.jcrc.2014.03.002

17 Herzig SJ, Howell MD, Ngo LH, Marcantonio ER. Acid-suppressive medication use and the risk for hospital-acquired pneumonia. IAMA 2009:301:2120-8. doi:10.1001/jama.2009.722

18 Siemieniuk RA, Agoritsas T, Macdonald H, Guyatt GH, Brandt L, Vandvik PO. Introduction to BMJ Rapid Recommendations. BMJ 2016;354:i5191. doi:10.1136/bmj.i5191

19 Deeks J, Higgins J, Altman D, et al. Cochrane handbook for systematic reviews of interventions version 5.1. O (updated March 2011). The Cochrane Collaboration, 2011.

20 Egger M, Davey Smith G, Schneider M, Minder C. Bias in metaanalysis detected by a simple, graphical test. BMJ 1997;315:629-34. doi:10.1136/bmj.315.7109.629

21 Ades AE, Sculpher M, Sutton A, et al. Bayesian methods for evidence synthesis in cost-effectiveness analysis. Pharmacoeconomics 2006;24:119. doi:10.2165/00019053-200624010-00001

22 Lumley T. Network meta-analysis for indirect treatment comparisons. Stat Med 2002:21:2313-24. doi:10.1002/sim.1201

23 Dias S, Sutton AJ, Ades AE, Welton NJ. Evidence synthesis for decision making 2: a generalized linear modeling framework for pairwise and network meta-analysis of randomized controlled trials. Med Decis Making 2013;33:607-17. doi:10.1177/0272989X12458724

24 Marinho VC, Worthington HV, Walsh T, Chong LY. Fluoride gels for preventing dental caries in children and adolescents. Cochrane Database Syst Rev 2015;(6):CD002280. doi:10.1002/14651858. CD002280.pub2

25 van Valkenhoef G, Dias S, Ades AE, Welton NJ. Automated generation of node-splitting models for assessment of inconsistency in network meta-analysis. Res Synth Methods 2016;7:80-93. doi:10.1002/ jrsm.1167

26 Chaimani A, Salanti G. Using network meta-analysis to evaluate the existence of small-study effects in a network of interventions. Res Synth Methods 2012:3:161-76. doi:10.1002/jrsm.57

27 Brignardello-Petersen R, Murad MH, Walter SD, et al, GRADE Working Group. GRADE approach to rate the certainty from a network meta-analysis: avoiding spurious judgments of imprecision in sparse networks. J Clin Epidemiol 2019;105:60-7. doi:10.1016/j. jclinepi.2018.08.022

28 Brignardello-Petersen R, Mustafa RA, Siemieniuk RAC, et al, GRADE Working Group. GRADE approach to rate the certainty from a network meta-analysis: addressing incoherence. J Clin Epidemiol 2019;108:77-85. doi:10.1016/j.jclinepi.2018.11.025

29 Chaimani A, Higgins JP, Mavridis D, Spyridonos P, Salanti G. Graphical tools for network meta-analysis in STATA. PLoS One 2013;8:e76654 doi:10.1371/journal.pone.0076654

30 Balshem H, Helfand M, Schünemann HJ, et al. GRADE guidelines: 3. Rating the quality of evidence. J Clin Epidemiol 2011;64:401-6. doi:10.1016/j.jclinepi.2010.07.015

31 Brignardello-Petersen R, Bonner A, Alexander PE, et al, GRADE Working Group. Advances in the GRADE approach to rate the certainty in estimates from a network meta-analysis. / Clin Epidemiol 2018;93:36-44. doi:10.1016/j.jclinepi.2017.10.005

32 Guyatt GH, Oxman AD, Vist GE, et al, GRADE Working Group. GRADE: an emerging consensus on rating quality of evidence and strength of recommendations. BMJ 2008;336:924-6. doi:10.1136/ bmj.39489.470347.AD

33 Puhan MA, Schünemann HJ, Murad MH, et al, GRADE Working Group. A GRADE Working Group approach for rating the quality of treatment effect estimates from network meta-analysis. BMJ 2014;349:g5630. doi:10.1136/bmj.g5630

34 Guyatt GH, Oxman AD, Kunz R, et al. GRADE guidelines 6. Rating the quality of evidence-imprecision. / Clin Epidemiol 2011;64:1283-93. doi:10.1016/j.jclinepi.2011.01.012

35 Guyatt GH, Oxman AD, Kunz R, et al, GRADE Working Group. GRADE guidelines: 8. Rating the quality of evidence-indirectness. J Clin Epidemiol 2011;64:1303-10. doi:10.1016/j.jclinepi.2011.04.014

36 Guyatt GH, Oxman AD, Kunz R, et al, GRADE Working Group. GRADE guidelines: 7. Rating the quality of evidence-inconsistency. J Clin Epidemiol 2011;64:1294-302. doi:10.1016/j.jclinepi.2011.03.017

37 Guyatt GH, Oxman AD, Montori V, et al. GRADE guidelines: 5. Rating the quality of evidence-publication bias. J Clin Epidemiol 2011;64:1277-82. doi:10.1016/j.jclinepi.2011.01.011

38 Guyatt GH, Oxman AD, Vist G, et al. GRADE guidelines: 4. Rating the quality of evidence-study limitations (risk of bias). J Clin Epidemiol 2011;64:407-15. doi:10.1016/j.jclinepi.2010.07.017

39 Apte NM, Karnad DR, Medhekar TP, Tilve GH, Morye S, Bhave GG Gastric colonization and pneumonia in intubated critically ill patients receiving stress ulcer prophylaxis: a randomized, controlled trial. Crit Care Med 1992;20:590-3. doi:10.1097/00003246-19920500000008

40 Bashar FR, Manuchehrian N, Mahmoudabadi M, Hajiesmaeili MR, Torabian S. Effects of ranitidine and pantoprazole on ventilatorassociated pneumonia: a randomized double-blind clinical trial. Tanaffos 2013;12:16-21

41 Ben-Menachem T, Fogel R, Patel RV, et al. Prophylaxis for stress-related gastric hemorrhage in the medical intensive care unit. A randomized, controlled, single-blind study. Ann Intern Med 1994;121:568-75. doi:10.7326/0003-4819-121-8199410150-00003

42 Burgess P, Larson GM, Davidson P, Brown J, Metz CA. Effect of ranitidine on intragastric $\mathrm{pH}$ and stress-related upper gastrointestinal bleeding in patients with severe head injury. Dig Dis Sci 1995:40:645-50. doi:10.1007/BF02064385

43 Cannon LA, Heiselman D, Gardner W, Jones J. Prophylaxis of upper gastrointestinal tract bleeding in mechanically ventilated patients. A randomized study comparing the efficacy of sucralfate, cimetidine, and antacids. Arch Intern Med 1987;147:2101-6. doi:10.1001/ archinte.1987.00370120037009

44 Chan KH, Lai EC, Tuen H, et al. Prospective double-blind placebocontrolled randomized trial on the use of ranitidine in preventing postoperative gastroduodenal complications in high-risk neurosurgical patients. / Neurosurg 1995;82:413-7. doi:10.3171/ jns.1995.82.3.0413

45 Conrad SA, Gabrielli A, Margolis B, et al. Randomized, double-blind comparison of immediate-release omeprazole oral suspension versus 
intravenous cimetidine for the prevention of upper gastrointestinal bleeding in critically ill patients. Crit Care Med 2005;33:760-5. doi:10.1097/01.CCM.0000157751.92249.32

46 Cook D, Guyatt G, Marshall J, et al, Canadian Critical Care Trials Group. A comparison of sucralfate and ranitidine for the prevention of upper gastrointestinal bleeding in patients requiring mechanical ventilation. N Engl J Med 1998;338:791-7. doi:10.1056/ NEJM199803193381203

47 De Azevedo JRA, Soares MDGA, Silva GAE, et al. Prevention of stress ulcer bleeding in high risk patients. Comparison of three drugs. Gastrenterologia Endoscopia Digestiva 2000;19:239-44.

48 Eddleston JM, Pearson RC, Holland J, Tooth JA, Vohra A, Doran BH. Prospective endoscopic study of stress erosions and ulcers in critically ill adult patients treated with either sucralfate or placebo. Crit Care Med 1994;22:1949-54. doi:10.1097/00003246199422120-00010

49 Fink M, Karlstadt RG, Maroko RT, et al. Intravenous pantoprazole (IVP) and continuous infusion cimetidine (C) prevent upper gastrointestinal bleeding (UGIB) regardless of APSII score (APACHE II) in high risk intensive care unit (ICU) patients. Gastroenterology 2003;124:A62526. doi:10.1016/S0016-5085(03)83170-0

50 Groll A, Simon JB, Wigle RD, Taguchi K, Todd RJ, Depew WT. Cimetidine prophylaxis for gastrointestinal bleeding in an intensive care unit. Gut 1986;27:135-40. doi:10.1136/gut.27.2.135

51 Gursoy 0, Memiş D, Sut N. Effect of proton pump inhibitors on gastric juice volume, gastric $\mathrm{pH}$ and gastric intramucosal $\mathrm{pH}$ in critically ill patients : a randomized, double-blind, placebo-controlled study. Clin Drug Investig 2008;28:777-82. doi:10.2165/0044011 200828120-00005

52 Halloran LG, Zfass AM, Gayle WE, Wheeler CB, Miller JD. Prevention of acute gastrointestinal complications after severe head injury: a controlled trial of cimetidine prophylaxis. Am J Surg 1980;139:44-8. doi:10.1016/0002-9610(80)90228-7

53 Hanisch EW, Encke A, Naujoks F, Windolf J. A randomized, doubleblind trial for stress ulcer prophylaxis shows no evidence of increased pneumonia. Am / Surg 1998;176:453-7. doi:10.1016/S00029610(98)00239-6

54 Harlaftis N, Basdanis G, Papapolychroniadis C, et al. Nosocomial pneumonia in mechanically ventilated patients during stress ulcer prophylaxis with sucralfate and ranitidine. Hell Gastroenterol 1997;10:230-5.

55 Jakob SM, Parviainen I, Ruokonen E, Uusaro A, Takala J. Lack of effect of ranitidine on gastric luminal $\mathrm{pH}$ and mucosal $\mathrm{PCO} 2$ during the first day in the ICU. Acta Anaesthesiol Scand 2005;49:390-6. doi:10.1111/j.1399-6576.2005.00651.x

56 Kantorova I, Svoboda P, Scheer P, et al. Stress ulcer prophylaxis in critically ill patients: a randomized controlled trial. Hepatogastroenterology 2004;51:757-61.

57 Karlstadt RG, Iberti TJ, Silverstein J, et al. Comparison of cimetidine and placebo for the prophylaxis of upper gastrointestinal bleeding due to stress-related gastric mucosal damage in the intensive care unit. J Intensive Care Med 1990;5:26-32. doi:10.1177/088506669000500106

58 Kaushal S, Midha V, Sood A, et al. A comparative study of the effects of famotidine and sucralfate in prevention of upper gastro-intestinal bleeding in patients of head injury. Indian J Pharmacol 2000;32:246-9.

59 Khorvash F, Abbasi S, Meidani M, Dehdashti F, Ataei B. The comparison between proton pump inhibitors and sucralfate in incidence of ventilator associated pneumonia in critically ill patients. Adv Biomed Res 2014;3:52. doi:10.4103/2277-9175.125789

60 Labattut AG, Santolalla PM, De Andres AP, et al. Efficacy of sucralfate in the prevention of upper gastrointestinal stress bleeding in intensive care patients: comparison vs a control group. Clin Intensive Care 1992:3:S19-25.

61 Laggner AN, Lenz K, Base W, Druml W, Schneeweiss B, Grimm G. Prevention of upper gastrointestinal bleeding in long-term ventilated patients. Sucralfate versus ranitidine. Am J Med 1989;86(6A):81-4. doi:10.1016/0002-9343(89)90164-2

62 Laggner AN, Lenz K, Graninger W, et al. Stress ulcer prophylaxis in a general intensive care unit: sucralfate versus ranitidine [in German]. Anaesthesist 1988;37:704-10

63 Lee TH, Hung FM, Yang LH. Comparison of the efficacy of esomeprazole and famotidine against stress ulcers in a neurosurgical intensive care unit. Advances in Digestive Medicine 2014;1:50-3. doi:10.1016/i.aidm.2013.06.001

64 Levy MJ, Seelig CB, Robinson NJ, Ranney JE. Comparison of omeprazole and ranitidine for stress ulcer prophylaxis. Dig Dis Sci 1997:42:1255-9. doi:10.1023/A:1018810325370

65 Lin CC, Hsu YL, Chung CS, Lee TH. Stress ulcer prophylaxis in patients being weaned from the ventilator in a respiratory care center: $\mathrm{A}$ randomized control trial. J Formos Med Assoc 2016;115:19-24 doi:10.1016/i.jma.2014.10.006

66 Liu BL, Li B, Zhang X, et al. A randomized controlled study comparing omeprazole and cimetidine for the prophylaxis of stress-related upper gastrointestinal bleeding in patients with intracerebral hemorrhage. J Neurosurg 2013;118:115-20. doi:10.3171/2012.9.JNS12170

67 Lou W, Xia Y, Xiang P, et al. Prevention of upper gastrointestinal bleeding in critically ill Chinese patients: a randomized, doubleblind study evaluating esomeprazole and cimetidine. Curr Med Res Opin 2018;34:1449-55. doi:10.1080/03007995.2018.1464132

68 Macdougall BR, Bailey RJ, Williams R. H2-receptor antagonists and antacids in the prevention of acute gastrointestinal haemorrhage in fulminant hepatic failure. Two controlled trials. Lancet 1977;1:617-9. doi:10.1016/S0140-6736(77)92055-4

69 Martin LF, Booth FV, Karlstadt RG, et al. Continuous intravenous cimetidine decreases stress-related upper gastrointestinal hemorrhage without promoting pneumonia. Crit Care Med 1993;21:19-30. doi:10.1097/00003246-199301000-00009

70 Nielsen HJ, Witt K, Moesgaard F, Kehlet H. Ranitidine for improvement of delayed hypersensitivity response in patients with sepsis. Acta Chir Scand 1989;155:445-9.

71 Nourian A, Mohammadi M, Beigmohammadi MT, et al. Comparing efficacy of enteral nutrition plus ranitidine and enteral nutrition alone as stress ulcer prophylaxis. J Comp EffRes 2018;7:493-501. doi:10.2217/cer-2017-0098

72 Peura DA, Johnson LF. Cimetidine for prevention and treatment of gastroduodenal mucosal lesions in patients in an intensive care unit. Ann Intern Med 1985;103:173-7. doi:10.7326/0003-4819103-2-173

73 Pickworth KK, Falcone RE, Hoogeboom JE, Santanello SA. Occurrence of nosocomial pneumonia in mechanically ventilated trauma patients: a comparison of sucralfate and ranitidine. Crit Care Med 1993;21:1856-62. doi:10.1097/00003246-19931200000012

74 Powell H, Morgan M, Li SK, et al. Inhibition of gastric acid secretion in the intensive care unit after coronary artery bypass graft. A pilot control study of intravenous omeprazole by bolus and infusion, ranitidine and placebo. Theor Surg 1993;8:125-30.

75 Prakash S, Rai A, Gogia AR, et al. Nosocomial pneumonia in mechanically ventilated patients receiving ranitidine or sucralfate as stress ulcer prophylaxis. Indian J Anaesth 2008;52:179-84.

76 Prod'hom G, Leuenberger P, Koerfer J, et al. Nosocomial pneumonia in mechanically ventilated patients receiving antacid, ranitidine, or sucralfate as prophylaxis for stress ulcer. A randomized controlled trial. Ann Intern Med 1994;120:653-62. doi:10.7326/0003-4819. 120-8-199404150-00005

77 Reusser P, Gyr K, Scheidegger D, Buchmann B, Buser M, Zimmerli W. Prospective endoscopic study of stress erosions and ulcers in critically ill neurosurgical patients: current incidence and effect of acid-reducing prophylaxis. Crit Care Med 1990;18:270-4. doi:10.1097/00003246-199003000-00004

78 Ruiz-Santana S, Ortiz E, Gonzalez B, Bolaños J, Ruiz-Santana AJ, Manzano JL. Stress-induced gastroduodenal lesions and total parenteral nutrition in critically ill patients: frequency, complications, and the value of prophylactic treatment. A prospective, randomized study. Crit Care Med 1991;19:887-91. doi:10.1097/00003246199107000-00011

79 Ryan P, Dawson J, Teres D, Celoria G, Navab F. Nosocomial pneumonia during stress ulcer prophylaxis with cimetidine and sucralfate. Arch Surg 1993;128:1353-7. doi:10.1001/ archsurg.1993.01420240061011

80 Selvanderan SP, Summers MJ, Finnis ME, et al. Pantoprazole or placebo for stress ulcer prophylaxis (POP-UP): randomized double-blind exploratory study. Crit Care Med 2016;44:1842-50. doi:10.1097/CCM.0000000000001819

81 Solouki M, Mar'ashian SM, Koochak M et al. Ventilator-associated pneumonia among ICU patients receiving mechanical ventilation and prophylaxis of gastrointestinal bleeding. Iran J Clin Infect Dis 2009; 4:177-80.

82 Solouki M, Marashian SM, Kouchak M, et al. Comparison between the preventive effects of ranitidine and omeprazole on upper gastrointestinal bleeding among ICU patients. Tanaffos 2009;8:37-42.

83 Somberg L, Morris JJr, Fantus R, et al. Intermittent intravenous pantoprazole and continuous cimetidine infusion: effect on gastric $\mathrm{pH}$ control in critically ill patients at risk of developing stress-related mucosal disease. J Trauma 2008;64:1202-10. doi:10.1097/ TA.0b013e31815e40b5

84 Spapen H, Diltoer M, Nguyen DN, Ingels G, Ramet J, Huyghens L. One week treatment with cimetidine does not attenuate the cortisol response to a short corticotropin test in stable intensive care patients: a prospective, randomized, and controlled study. Acta Anaesthesiol Belg 1995;46:133-40.

85 Thomason MH, Payseur ES, Hakenewerth AM, et al. Nosocomial pneumonia in ventilated trauma patients during stress ulcer prophylaxis with sucralfate, antacid, and ranitidine. Trauma 1996;41:503-8. doi:10.1097/00005373-19960900000020 
86 Tryba M, Zevounou F, Torok M, Zenz M. Prevention of acute stress bleeding with sucralfate, antacids, or cimetidine. A controlled study with pirenzepine as a basic medication. Am J Med 1985;79(2C):5561. doi:10.1016/0002-9343(85)90574-1

87 Zinner M], Zuidema GD, Mignosa M, Smith P[L. The prevention of upper gastrointestinal tract bleeding in patients in an intensive care unit. Surg Gynecol Obstet 1981;153:214-20.

88 Sun X, Briel M, Walter SD, Guyatt GH. Is a subgroup effect believable? Updating criteria to evaluate the credibility of subgroup analyses. BMJ 2010;340:c117. doi:10.1136/bmj.c117

89 Darlong V, Jayalakhsmi TS, Kaul HL, Tandon R. Stress ulcer prophylaxis in patients on ventilator. Trop Gastroenterol 2003:24:124-8.

90 Fabian TC, Boucher BA, Croce MA, et al. Pneumonia and stress ulceration in severely injured patients. A prospective evaluation of the effects of stress ulcer prophylaxis. Arch Surg 1993;128:185-91, discussion 191-2. doi:10.1001/archsurg 1993.01420140062010

91 Fogas JF, Kiss KK, Gyura FG, et al. Effects of proton pump inhibitor versus $\mathrm{H} 2$-receptor antagonist stress ulcer prophylaxis on ventilatorassociated pneumonia: A pilot study. Crit Care 2013;17:S150-51. doi:10.1186/cc12340

92 Hummer-Sigiel M, Jacquier A, Girard A, et al. Ranitidine pour la prophylaxie de l'ulcére de stress chexz les traumatisés crâniens graves. Ann Med Nancy l'Est 1986;25:101-3.

93 Kotlyanskaya A, Luka B, Mukherji R, et al. A comparison trial of lansoprazole disintegrating tablet, lansoprazole suspension or ranitidine for stress ulcer prophylaxis in critically ill patients. Crit Care Med 2007;35:A194-94

94 Phillips J, Metzler M, Huckfeldt R, et al. A multicenter, prospective, randomized clinical trial of continuous infusion i.v. ranitidine vs. omeprazole suspension in the prophylaxis of stress ulcers. Crit Care Med 1998;26:101A. doi:10.1097/00003246-199801001-00280

95 Simms HH, DeMaria E, McDonald L, Peterson D, Robinson A, Burchard KW. Role of gastric colonization in the development of pneumonia in critically ill trauma patients: results of a prospective randomized trial. J Trauma 1991;31:531-6, discussion 536-7. doi:10.1097/00005373-199104000-00013

96 Wee B, Liu CH, Cohen H, et al. IV famotidine vs. IV pantoprazole for stress ulcer prevention in the ICU: A prospective study. Crit Care Med 2013;41:A181. doi:10.1097/01.ccm.0000439969.36301.c9

97 Bhanot RD. Nosocomial pneumonia in mechanically ventilated patients receiving ranitidine, omeprazole or sucralfate as stress ulce prophylaxis. Am / Respir Crit Care Med 2010;181:A6039.

98 Metz CA, Livingston DH, Smith JS, Larson GM, Wilson TH, The Ranitidine Head Injury Study Group. Impact of multiple risk factors and ranitidine prophylaxis on the development of stress-related upper gastrointestinal bleeding: a prospective, multicenter double-blind, randomized trial. Crit Care Med 1993;21:1844-9. doi:10.1097/00003246-199312000-00010

99 Mustafa NA, Aktürk G, Ozen I, Köksal I, Erciyes N, Solak M. Acute stress bleeding prophylaxis with sucralfate versus ranitidine and incidence of secondary pneumonia in intensive care unit patients. Intensive Care Med 1995;21:287. doi:10.1007/BF01701491

100 Basso N, Bagarani M, Materia A, Fiorani S, Lunardi P, Speranza V. Cimetidine and antacid prophylaxis of acute upper gastrointestina bleeding in high risk patients. Controlled, randomized trial. Am J Surg 1981:141:339-41. doi:10.1016/0002-9610(81)90191-4
101 Brophy GM, Brackbill ML, Bidwell KL, Brophy DF. Prospective, randomized comparison of lansoprazole suspension, and intermittent intravenous famotidine on gastric $\mathrm{pH}$ and acid production in critically ill neurosurgical patients. Neurocrit Care 2010;13:176-81. doi:10.1007/s12028-010-9397-3

102 Cartier F, Gauthier-Lafaye P, Lareng L, et al. Cimetidine in patients at risk of stress ulcers: a multi-centre controlled trial. Intensive Care Med 1980;6:54.

103 Friedman CJ, Oblinger MJ, Suratt PM, et al. Prophylaxis of upper gastrointestinal hemorrhage in patients requiring mechanical ventilation. Crit Care Med 1982;10:316-9. doi:10.1097/00003246 198205000-00006

104 Larson GM, Davidson P, Brown J, et al. Comparison of ranitidine versus placebo on 24-hour gastric $\mathrm{Ph}$ and upper gastrointestinal (UGI) bleeding in head injury patients. Am J Gastroenterol 1989:84:1165.

105 Luk GD, Summer WR, Messersmith JF. Cimetidine and antacid in prophylaxis of acute gastrointestinal bleeding: a randomized, doubleblind, controlled study. Gastroenterology 1982;82:1121.

106 Pan X, Zhang W, Li Z, et al. The preventive effects of rabeprazole on upper gastrointestinal tract hemorrhage in patients with severe acute pancreatitis [Chinese]. Chinese Journal of Gastroenterology 2004:30-2.

107 van den Berg B, van Blankenstein M. Prevention of stress-induced upper gastrointestinal bleeding by cimetidine in patients on assisted ventilation. Digestion 1985;31:1-8. doi:10.1159/000199170

Appendix 1: Search terms and strategies Appendix 2: List of risk factors identified from included trials

Appendix 3: Study characteristics and outcome definition Appendix 4: Risk of bias of included studies Appendix 5: Network plots for each outcome Appendix 6: Network meta-analysis results for clinically important gastrointestinal bleeding and overt gastrointestinal bleeding using different models Appendix 7: Cumulative ranking of interventions for different outcomes

Appendix 8: GRADE summary of findings for other outcomes

Appendix 9: Meta-regression and subgroup analysis Appendix 10: Subgroup analysis for risk of bias for clinically important gastrointestinal bleeding and overt gastrointestinal bleeding

Appendix 11: Baseline risk of clinically important gastrointestinal bleeding and overt gastrointestinal bleeding for each risk group 
